\title{
Dialogue as A Means Of Developing Students' Communicative Literacy
}

\author{
Gafurova Gulrukh Baxtiyarovna
}

Jizzakh State Pedagogical Institute named by Abdulla Khadiri, English Faculty, Practical English Language Department, e-mail: gulruh8586@mail.ru

\section{ABSTRACT}

The sphere of communication in general over the past two decades has attracted the attention of researchers. The nature of communication, its age and individual characteristics, mechanisms of course and change have become the subject of study by philosophers and sociologists, psycholinguists, specialists in the field of social child and age psychology. Most scientific research and psychological and pedagogical recommendations on the formation of communication skills are dedicated to childhood. Studies of the communicative skills of preschoolers were devoted to such scientists as A.V. Hawks, E.R. Saitbaev. The approaches to teaching communication, forming a communicative function are felt much more slowly than in other areas of pedagogy and psychology. This is because a child can be taught, for example, to draw (take his hand), but to physically help him speak is much more difficult. For graduates of schools it is necessary to be sociable, contact in various social groups, to be able to work together in different areas, preventing conflict situations or skillfully getting out of them. These skills should provide the young man with mobility, the ability to quickly respond in a changing world with a state of mental comfort, which provides emotional balance. In modern conditions, dialogue takes on a new meaning and quality, acting as the basic principle of the communicative content of education. A multicultural society, saturated with diverse communicative ties, involves not only the establishment of relations of cooperation, mutual understanding, but also the emergence of contradictions, polemic disputes. Therefore, the ability of school graduates to conduct a fruitful, effective dialogue in various fields of the sociocultural sphere, to learn the world not from monological (with a claim to absolute truth), but dialogically, pluralistically becomes the most important and communicative property. Meanwhile, observations of the experience of discussions, political meetings and rallies, business meetings, scientific conferences give reason to conclude that in many speeches there is no deliberation, depth and credibility of arguments, consistency and consistency of reasoning, compliance with ethical standards, flexibility of thinking and speed reactions. They still "see" the monopoly on truth, a special style of communication and belief with its monologue moral teachings and harsh, peremptory judgments. In this regard, communicatively-oriented education departs from the monologic way of teaching and reorientes to the dialogical one, which promotes the development of communicative properties among schoolchildren, namely: the ability to discuss, agree, argue, prove, agree (or disagree) [8]. In order for a modern graduate to possess these skills, it is necessary that he be taught this. This requires appropriate organization of the educational process of modern schools, lyceums and gymnasiums. In connection with the relevance of this problem, a research topic arises - Dialogue, as a means of developing students' communicative literacy.

Keywords:

Students' communicative literacy, essence of the dialogue, the use of dialogue in foreign language lessons.

Article Received: 18 October 2020, Revised: 3 November 2020, Accepted: 24 December 2020

\section{Introduction}

Communicative literacy - knowledge of the rules of communication, the ability to correlate them with a specific situation (communicative lotus). It includes the culture of speech, language and speech literacy, knowledge of pedagogy and psychology of communication, knowledge of the logic and ethics of communication.

Communicativeness - ability, tendency to communication (transfer of information in the process of communication), to establish contacts, connections to communication.
In the scientific and pedagogical literature, communication, speech communication, communicative behavior, communicative education / training are relatively new concepts that are not adequately reflected not only in their pedagogical. But also in their general semantic meaning (for example, representatives of social sciences, including educational researchers, with whom I have to discuss these topics, they often ask the question, what is the difference between communication and speaking, a question despite the obvious "semantics", conceptual). So far, the 
whole area of knowledge that studies the phenomenon of human communication has not received an unambiguous name. Among the terms that are currently being "tried" in Uzbek, one can hear such as "communication science", "communication disciplines", "communication theory", "communication practice", etc.

The basis of the formation of communicative literacy is an activity approach, since it provides independent creative activity for each student. The approach is based on the position of P.Y. Galperin that in the independent creative activity of each student it is necessary to go from external practical material actions to internal, theoretical, ideal ones. That is, training involves at the first stage a joint educational and cognitive activity under the guidance of a teacher, and then independent. This is a "zone of proximal development", which must be taken into account when forming communicative literacy.

This approach is not opposed to the traditional, but not identical to it, since it fixes and establishes the subordination of knowledge and skills, putting emphasis on the practical side of the issue, expanding the content with personal components.

In order for the formation of communicative literacy to be effective, more successful, in order to create optimal conditions for the promotion of each student, it is necessary to know the educational opportunities of students of this age.

\section{Materials and methods}

The object of the study is the communicative literacy of students.

The subject of the study is dialogue, as a means of forming students' communication skills.

The aim of the study is to study the dialogue and its functions in learning.

Research Objectives:

- substantiate the concept of communicative literacy of students.

- study articles in periodicals devoted to this problem;
- reveal the essence of the dialogue and show its application in the lessons of a foreign language.

Research methods are the analysis of the available literature on the topic, showing illustrative examples.

\section{Results and discussion}

Human being is always "being with others." The quality of human life, hopes for happiness, human success are associated with the ability to properly build interaction with various people, communicate effectively. In the field of education, communication, on the one hand, is a means of cognition and familiarization with the truth, on the other hand, communication is about social and cultural values, ideals and norms between all participants in the educational process. In connection with the complication of all forms of communication in the educational space, increasing the amount of educational information, the diversity of its sources and carriers in the modern sociocultural situation, the priority of the development of students' communicative culture [9] becomes obvious.

Communicative culture is understood as the ability to establish and maintain contacts with other people on the basis of internal resources necessary to build an effective communicative action in situations of interpersonal communication. Based on the study of psychological and pedagogical literature, it can be stated that the mastery of students in a communicative culture involves, at a minimum, the development of three groups of skills.

I group of skills - communication or speech: the ability to clearly and clearly state thoughts; ability to convince; ability to argue; ability to build evidence; ability to make judgments; ability to analyze the utterance.

II group of skills - perception skills (perceptual): listening and hearing skills (correctly interpret information, including non-verbal (facial expressions, postures and gestures), understand subtexts, etc.), the ability to understand the feelings and mood of another person (the ability to 
empathy), observance of tact, empathy), the ability to analyze (the ability to reflection and selfreflection).

III group of skills - the ability to interact in the process of communication (interactive): the ability to conduct conversations, negotiations, discussions, the ability to politely express thoughts, the ability to ask questions, the ability to captivate oneself, the ability to formulate a requirement, the ability to communicate in conflict situations, the ability to control one's behavior in communication [1].

The solution of the problem of the development and establishment of a communicative culture makes it necessary to organize such special communicative relationships in the educational process that can be described as a dialogue. Education and upbringing of a spiritually developed, responsible person is possible only in dialogue. It is dialogue as a special level of the communicative process that meets the needs of a person in deep personal contact. Only in dialogue does the ability to think critically develop. In conversation, in asking, conditions are created for the interaction of understanding consciousnesses.

Thus, dialogue today is not just a pedagogical method and form, but it is becoming a priority principle of education. Dialogization of the educational process can be characterized by special mutually overlapping communication links, which are simultaneously hierarchically determined levels of communication.

The first connection: the self-image of culture (teacher-content, student-content) can be traced at the level of subject and content and involves a dialogue of cultural images. Dialogue as a method becomes a leading one, a priority - the task of the teacher is to provide the student with an interlocutor, to ensure that students are included in the culture through entry into the dialogue. Dialogization of the content of education at this level is implemented:

- through the appeal of education to a holistic picture of the world, and, above all, the world of culture, the world of man, through the "humanization" of knowledge, the formation of humanitarian thinking as a systemic thinking;

- through filling school education with humanitarian knowledge and building meaningful and value contexts;

- through reorientation of the content of education to the problems of human life;

- through the integration of natural-scientific and socio-humanitarian knowledge. Whatever components of knowledge about a person are considered, an element of sociality will necessarily be present in them. It seems that from today's point of view a unified approach is needed according to the criterion of natural (social);

- through the expansion of the system of knowledge about a person (enrichment and restructuring of educational content), through socio-psychological education. The assignment of social and psychological knowledge by students. Knowledge about a person (content of educational disciplines, subjects: valeology, history, literature, etc.); knowledge of oneself, of how to adequately interact with other people;

- through the reorientation of the vector of education from turning to the past, to turning to the present and the future (student, country, all of humanity).

The second connection: I am the other (student-student, teacher-student). At this level, the teacher's personal attitude to the student is emphasized, the teacher must also skillfully create psychological and pedagogical conditions for the emergence of personal contacts in a group of students, which requires him to master the technology of organizing productive interaction. This implies:

- application of humanitarian technologies in the educational process;

- enriching the experience of communication as a personality-forming factor, through the acquisition of experience in communicating with peers in various groups in the lesson and school communities; 
- harmonization of the principles of individualism and collectivism through the implementation of true human solidarity in the organization of school life;

- organization of special activities to develop communication skills and abilities (games, trainings of socially acceptable behavior).

The third connection: I-myself (teacher, student). Management of the third connection implies mastering both the student and the teacher by special technologies of self-understanding and self-regulation in communication (understanding feedback signals in face-to-face communication situations, mastering diagnostic methods, testing, recognizing one's strengths and weaknesses, correcting and modeling techniques for positive image) [3].

However, in the practice of modern schools, instruction continues to be monologous. A widespread joke among schoolchildren - "the school is a place where the child is answered questions that he did not ask" - reflects one of the central and unsolved tasks of pedagogy: filling the content of education with problems that concern the student himself.

The monological form of communication in the dyad "student-teacher" is based on the following distinctive features:

- status dominance, "subject-object relations";

- egocentrism, focusing on achieving one's own needs, goals and objectives;

- coercing students through covert manipulation or overt aggression;

- dogmatism, transpersonal translation of norms and knowledge subject to unconditional copying and assimilation;

- rigidity and stereotyped methods and techniques of exposure, the prevalence of disciplinary methods;

- subjectivity and hard polarization of grades, a narrow range of criteria for assessing student behavior.

Productive communication involves the unconditional acceptance and recognition of a communication partner. In the Russian scientific school, these ideas were brilliantly embodied in the discoveries of A.A. Ukhtomsky, who considered it necessary "to be able to specifically approach each individual person, to be able to enter his shell, heal his life, consider in another not just something equivalent to you, but also value the other above his own interests, being distracted from biases, prejudices and theories." The thinker identifies three functions of productive communication, realized through the "category of person", "the idea of the Honored Interlocutor", "the education of the dominant on the face of another person" [11].

The projecting perception, the view "through the prism of its dominants" - needs, experiences, emotions, feelings - has its negative and positive sides. Its effectiveness depends on the moral culture of the teacher.

The need for emotional support and understanding is not one-sided - "teacher - student." Requires perceptual feedback. The teacher also needs understanding and approval of his actions from the students. The teacher needs protection from his students even more than they are in his patronage. For the student, understanding by peers is especially significant. The child's lack of experience with peers dulls the ability to understand other people. through the reorientation of the vector of education from turning to the past, to turning to the present and the future (student, country, all of humanity).

The second connection: I am the other (student-student, teacher-student). At this level, the teacher's personal attitude to the student is emphasized, the teacher must also skillfully create psychological and pedagogical conditions for the emergence of personal contacts in a group of students, which requires him to master the technology of organizing productive interaction. This implies:

- application of humanitarian technologies in the educational process;

- enriching the experience of communication as a personality-forming factor, through the acquisition of experience in communicating with 
peers in various groups in the lesson and school communities;

- harmonization of the principles of individualism and collectivism through the implementation of true human solidarity in the organization of school life;

- organization of special activities to develop communication skills and abilities (games, trainings of socially acceptable behavior).

The third connection: I-myself (teacher, student). Management of the third connection implies mastering both the student and the teacher by special technologies of self-understanding and self-regulation in communication (understanding feedback signals in face-to-face communication situations, mastering diagnostic methods, testing, recognizing one's strengths and weaknesses, correcting and modeling techniques for positive image) [3].

However, in the practice of modern schools, instruction continues to be monologous. A widespread joke among schoolchildren - "the school is a place where the child is answered questions that he did not ask" - reflects one of the central and unsolved tasks of pedagogy: filling the content of education with problems that concern the student himself.

The monological form of communication in the dyad "student-teacher" is based on the following distinctive features: status dominance, "subject-object relations"; egocentrism, focusing on achieving one's own needs, goals and objectives; coercing students through covert manipulation or overt aggression; dogmatism, transpersonal translation of norms and knowledge subject to unconditional copying and assimilation; rigidity and stereotyped methods and techniques of exposure, the prevalence of disciplinary methods; subjectivity and hard polarization of grades, a narrow range of criteria for assessing student behavior.

Productive communication involves the unconditional acceptance and recognition of a communication partner. These ideas were brilliantly embodied in the discoveries of Russian scientific school who considered it necessary "to be able to specifically approach each individual person, to be able to enter his shell, heal his life, consider in another not just something equivalent to you, but also value the other above his own interests, being distracted from biases, prejudices and theories." The thinker identifies three functions of productive communication, realized through the "category of person", "the idea of the Honored Interlocutor", "and the education of the dominant on the face of another person" [11].

The projecting perception, the view "through the prism of its dominants" - needs, experiences, emotions, feelings - has its negative and positive sides. Its effectiveness depends on the moral culture of the teacher.

The need for emotional support and understanding is not one-sided - "teacher - student." Requires perceptual feedback. The teacher also needs understanding and approval of his actions from the students. The teacher needs protection from his students even more than they are in his patronage. For the student, understanding by peers is especially significant. The child's lack of experience with peers dulls the ability to understand other people.

The following features are characteristic of the dialogical form of communication in the dyad "student-teacher":

- personal equality of the teacher and pupil, "subject-subject" relations;

- teacher's focus on the needs of the child;

- cooperation and consent;

- freedom of discussion, transfer of norms and knowledge as personal experience, requiring individual reflection;

- desire for creativity, personal and professional growth;

- desire for objective control over the activities of students, an individual approach to taking into account the polymotivation of their actions.

These technologies activate educational synergy - the co-creation of a teacher and student in the educational process. According to M.M. 
Bakhtin, truth is not born and is not in the head of an individual person, it is born between people who jointly discover the truth in the process of their dialogical communication [2].

With this approach, the interaction of the teacher and the student is interactive, spiritual, productive, eventful, and therefore dialogue.

Studying the process of interaction between a teacher and a student in a dialogue, we can distinguish such a criterion of its effectiveness as a movement towards the co-creation of a teacher and student. The creative movement vector is determined by the content of the culture.

We characterize three forms of dialogue interaction - unproductive, preproductive and productive.

The first form is unproductive. The interaction is carried out on a formal level, the monologous form prevails, the teacher does not create conditions for cooperation, the lack of movement towards co-creation through the student-teacher communication line.

The second form is preproductive. The interaction is carried out with the dominant role of the teacher, with the prevalence of the monologous form, a dialogue is partially introduced, the student appropriates certain facts, knowledge.

The third form is productive. The interaction is carried out on a personal level, relations of equal cooperation arise, the dialogical form prevails, and the student and teacher achieve co-creation during the lesson, which goes back to common meanings and values.

The educational impact is possible only with the implementation of the productive form, because the main mechanism of mental development in the process of humanitarian cognition is such a relationship of "I" and "not-I", such a "sacrament" as experience and complicity.

Today, education is becoming more and more recognized by our society as a sphere of investment in a person, in the better future of the state. Pupils and pupils more than ever need high professionalism, civic position and the pedagogical culture of educators. Only the teachers who understand and accept the tasks of education at the present stage can realize the best ideas for reforming education. Thus, the approval of the priorities of the educational dialogue in the educational space of the modern school, productive forms of pedagogical communication helps students to learn the communicative culture, fosters a creative and responsible personality, and therefore represents an urgent problem of the current stage of development of Russian education and our society as a whole.

Currently, the dialogue is interpreted as the basic principle of communicative education, a special didactic-communicative environment and at the same time educational technology based on "understanding" approaches that are adequate to the student's nature and his abilities.

It is considered significant in them that an understanding approach develops in schoolchildren the ability to think and reflect. The means to achieve this goal are the vocabulary, style and logic of the language of conversation, which develops among students a conscious, internally accepted skill of "moral" speech, which serves to form a moral personality. Adhering to this position, we see the essence of the understanding approach in the priority use of the philosophical language in the educational process, philosophical arguments aimed at the comprehensive study of an object or phenomenon and its inclusion in the students' worldview, at creating a holistic picture of the world. The participants of communication consider the object of their attention not only impartially analytically, but it occupies a certain place in the normative and value sphere of their personality, directly or indirectly forming their attitudes and beliefs.

Using this approach to teaching, a teacher solves two problems simultaneously: firstly, it helps students to become aware of a specific phenomenon; secondly, enriches them with the ability to think independently. As a result, he turns even the most absurd actions and ideas of students into a mechanism for going beyond the limits of stereotypes of thinking and developing certain 
worldviews. In this regard, we attach particular importance to understanding the specifics of the dialogical principle of communicative education in the idea of "philosophical education".

The philosophy of communicative education is based on working with the meanings of ordinary but deep concepts, such as freedom, life, justice, peace, goodness, etc., which cannot be discussed once and for all. In this regard, the dialogical principle is realized in the communicative activity of the teacher and students that is special in content - the meaning of activity is the activity of generating, developing and developing the personal meanings of its participants. Such an activity is not a static suggestion, achieved by simple memorization, but a lively, moving, changing process, carried out in unity with the emotional, motor and sensory activity of students. Accordingly, its implementation requires the teacher to use adequate techniques and procedures, such as observation, measurement, associativity [4].

With the help of observation, the teacher organizes the contact of students with material, fact. The measurement procedure allows you to make this contact tangible for all participants in the communication. Using associativity, he develops abstract thinking among schoolchildren, forms a categorical-conceptual apparatus, etc. Communicative methods of organizing the sense of activity are also special in their tasks and content: methods of experiencing, listening, peering, into feelings, etc. With their help, the teacher expresses constant attention to the student, to his word and the circumstances of the conversation, makes his anticipations (pre-compiled ideas about something or about someone) conscious. Understanding in this case is achieved by mutual listening, tracking interlocutors for each other's thoughts. To make sure that students understand, the teacher skillfully asks them questions expressing his sincere desire to find out the essence of their thoughts, the real value of their words.

As you can see, the dialogical principle, implemented within the framework of an understanding approach, requires an adequate teaching technology based on analysis procedures, comparison of students' initial intentions, analysis of fragments in which thoughts are distorted, etc. Particular attention is paid to a uniform interpretation of the terminology used, which plays a key role in building understanding of the relationship between teacher and students.

In the process of the educational dialogue, the teacher uses elements of the technology of communicative learning, namely:

- the diagnosis of students' readiness for dialogue, basic knowledge, communicative experience, installation on the presentation and perception of other points of view;

- the search for controversial motives, the processing of educational material into a system of educationally-conflicting issues and tasks, which implies a deliberate exacerbation of "collisions", elevating them to "eternal" human problems, designing methods for the interaction of communication participants, their roles. And conditions for their acceptance by students, hypothetical identification of zones improvisation (such situations of dialogue for which it is difficult to foresee the behavior of its participants) [3].

Dialogue as a creative interaction of people is not conceivable without questions and problems. Absolute agreement between partners is the death of dialogue. Dialogue is not possible neither in conditions of absolute dependence, nor in conditions of absolute autonomy of an individual. The concept of "dialogue", used in training, is used in three senses:

Each scientific concept is considered in the lessons as a dialogue of various logics, cultures, and ways of understanding. Consideration of scientific concepts in the "gap" of different logics provides the educational dialogue with the eternal problems of human existence, informs it of productive insolubility, incompleteness and, at the same time, depth. It is in this sense that we should speak of a dialogue of logics.

In the course of the educational dialogue, a special communication arises between the student 
and the teacher, in which the participants not only show one or another facet of ancient, medieval, modern thinking, but first of all feel for their own view of the world.

Educational dialogue is adequate to modern dialogical thinking only when the clash of cultural blocks is constantly interfaced with the internal dialogue of the thinker. This micro-dialogue proceeds in the form of a special internal speech, not the same as external speech.

In order for the educational task set by the teacher to generate educational dialogue, it must act as his point of view, a long-standing personal position that explodes the student's usual way of thinking, encouraging children to be creative. In order to provide an understanding of the material presented, the teacher must disclose not only the meaning of the element of the content of education, but also its meaning in the context of other elements of social experience. Education, therefore, is a form of communication, the teacher and student act as communicants of the dialogical relationship "teacher - student." The teacher should take into account that each of his students has his "out of find" position in relation to the teacher.

The teacher's professional task is to help the child see in the common problem that unique turn that is in contact with the student's personal problems and thoughts. It should not interfere with the process of redefining educational problems, and should not impede students from posing new problems in the lesson [5].

Owing to its universality, dialogue in training is not a plot, not a fragment of a lecture or seminar. The dialogue is always "in a non-plot" and independent of this or that situation in the lesson, although it is prepared by it. One cannot understand a dialogue teacher as a kind of information system working for a student. Such a teacher is characterized by deep attention to the problems of the student himself in the context of the dialogized content of instruction, that is, when the teacher and students go into the field of frontier problems of science, to the border of the known.
Like the student, the teacher is tormented by the problem posed in the lesson. For the teacher, she is as sharp as for the child. The teacher, like the children, offers his own individual solutions to the problem, poses his questions, and creates his own images. For children, dialogue is a feeling and understanding of equality with their interlocutor. Equality in dialogue is an inequality in knowledge these are equal rights to responsibility for posing and resolving one's own issue.

Dialogue lessons with a pre-prepared outcome are dangerous. A dialogue lesson offers tasks either having a number of solutions or not having solutions in principle.

A positive characteristic of the use of dialogs in the lessons for the formation of verbal-speech skills and communicative literacy of students:

Pupils speak the vast majority of the lesson. The teacher only guides and models various forms of speech interaction.

All students participate equally in communication. The teacher does not allow the monopolization of attention and study time by the group of the most relaxed and advanced students, involves poorly performing and shy ones in communication.

Students want to talk. The level of motivation in the lesson is very high due to the use of various sources of creating motivation.

The language level corresponds to the real possibilities of this group [6].

Speaking is a productive (expressive) type of speech activity, through which oral-verbal communication is carried out together with listening. The content of speaking is the expression of thoughts, the transmission of information orally.

Speaking as a type of speech activity is characterized by the following critical parameters:

1. motive - the need or need to speak out;

2. purpose and functions - the nature of the impact on the partner, the way of self-expression;

3. subject - own or someone else's thought;

4. structure - actions and operations;

5. mechanisms - understanding, anticipation, combination; 
6. means - language and speech material;

7. speech product - types of dialogues, monologic statements;

8. conditions - speech situations;

9. availability or absence of supports.

Speaking is based on productive pronunciation, rhythmic-intonational and lexicalgrammatical skills. Foreign language speaking as a complex integrated skill is distinguished by motivation, activity and independence of the speaker, purposefulness, connection with thinking, situational conditioning, heuristic. For a greater or lesser role of independence in programming oral speech, distinguish between initiative (active), reactive (response), and reproductive speech.

Speaking can proceed in a dialogical or monologic form or in a complex interweaving of dialogue and monologue, therefore, speaking skills include two groups of specific skills: dialogical and monological [9].

When teaching dialogic speech, it is recommended to establish the ultimate goal of teaching this type of speech activity and intermediate goals in relation to different levels of learning. To identify the stage of formation of basic dialogical skills and the stage of improvement of these skills in speech communication (group unprepared dialogue, thematic conversation), determine the nature of exercises, verbal and nonverbal supports and learning and speech situations.

Dialogue skills require the possession of a sufficient supply of functionally diverse replicas and include such private skills as:

- ability to replicate (exchange of remarks in dialogue and polylogue);

- the ability to pursue their strategic line in communication in accordance with the speech intentions of the interlocutors or in spite of their intentions;

- ability to take into account new speech partners;

- the ability to predict the behavior of interlocutors, the outcome of a particular situation [2].
Top-down dialogue training is the most optimal for teaching standard or standard dialogs.

The algorithm of the teacher's work in teaching dialogue in a foreign language by "top to bottom" [10]:

- Identify the most typical situations of dialogic communication within the framework of the topic being studied ("At the doctor", "Talking on the phone").

- Examine the materials of available textbooks corresponding to the age and level of the students' language.

- To select or compose dialogs-samples using speech clichés typical for a given situation, models of speech interaction.

- To determine the sequence of presentation of various standard dialogues in the process of studying the topic.

- To acquaint students with new words and speech structures of the presented dialogue.

- If necessary, comment on the sociocultural characteristics of verbal communication in the framework of this situation.

- Read the dialogue or play the recording.

- Organize its development, paying attention to the correctness of the phonetic design of speech, the use of other paralinguistic means.

- Organize work with the text of the dialogue, aimed at its full understanding and memorization, as well as partial transformation, taking into account already familiar synonymous models.

- Similarly, work out other typical dialogs.

- To partially modify the speech situation with the aim of introducing an element of authenticity into the solution of the speech problem, simulating the connection of replicas from various standard dialogs in students' speech.

- Formulate a speech installation for creative educational dialogs on the topic.

- Consider using verbal and non-verbal supports for specific students.

- Plan pairs of interviewed students and the sequence of their interviews. 
Support for compiling your own dialogues can serve:

1. The texts of the dialogue models;

2. The content of the teacher's speech installation to compose modified dialogs;

3. A description of the roles received separately by each of the participants in the dialogue;

4. Pictures or videos played without sound.

Example dialog model:

W: Hello, Sally!

B: Good afternoon, Mr. Adison!

W: Is Doctor Kelly in?

B: No, she is not. She is still in the hospital.

W: What a pity! By!

B: Good bye!

Learning from the bottom-up dialogue suggests that students do not have an initial dialogue sample, because:

1. Students cannot read and cannot use the sample;

2. The level of speech development is quite high, so a single sample is no longer needed;

3 . The alleged dialogue refers to a kind of free dialogue, and the sample will only impede the initiative and creativity of students.

In this case, it is not just about using dialogue, but about teaching a dialogic form of communication, therefore, students need to improve the following dialogic skills:

- ability to ask questions of various types;

- logically, consistently and clearly answer the questions posed;

- use different response lines in the communication process, showing interest, attention and active participation in the conversation;

- use various introductory structures and clichéd expressions;

- use various ways to implement speech functions, such as expressing consent or disagreement, doubt, satisfaction, request, etc. [7]

\section{Conclusions}

The purpose of our study was to substantiate the concept of communicative literacy of students and the study of dialogue, as a means of forming communicative literacy of students, and its functions in learning.

In accordance with the goal, a study was conducted, during which the tasks were completed.

Dialogization of the relationship between teacher and students enriches the possibilities of the learning process in terms of the implementation of all its components, improving the quality of knowledge, skills, the formation of experience in creative activity and the experience of emotional and evaluative attitudes and the logic of scientific thinking.

The dialogical form of communication is close in essence to a heuristic conversation, the analysis of which reveals the following components:

1) dividing the problem into sub problems,

2) the removal of some questions from others,

3) control over the consistency of issues and the adequacy of their totality,

4) accounting of all data for raising questions and solving problems,

5) access to additional data,

6) involuntary and arbitrary assumption of the next step,

7) correlation of the solution and the original problem.

In the process of dialogue, reproductive and productive (creative) teaching methods organically merge. The conditions are created for consolidating and using knowledge in new situations. The ability to ask a question in a dialogical form of communication reflects an understanding of the problem.

In addition, in the process of dialogue in a foreign language, students develop not only phonetic, but also lexical and grammatical skills, which contributes to a more intensive and productive study of a foreign language.

Learning about dialogue has an indispensable educational effect, because the very form of dialogic communication presumes respect for the speaker both in the form of an appeal to him and in 
reaction to the expression, in expressing agreement or disagreement with the point of view of the participants in the dialogue.

Communicative technologies that are actively developing today (computer communication, teleconference, distance learning, teleconferencing, the Internet, etc.) are becoming new cognition tools that students learn only through dialogue. As one of the fundamental principles of communicative education, he finds himself at all its levels: in the external form of training, in content that goes beyond purely logical subjectivity; in the means of implementation. We believe that it does not replace the whole variety of functions of the educational process, but acts as a special mechanism for the formation of a communicatively competent personality of the student. The specifics of the dialogical principle of communicative education and the ways of its implementation can be understood through understanding of its nature, the essence of dialogue in general and educational dialogue in particular.

\section{Acknowledgements}

I would like to express my gratitude to the stuff of Jizzakh State Pedagogical Institute named by Abdulla Khadiri and to the "Practical English Language" Department for their contribution while doing my research in the field of language education.

\section{References}

[1] Batrakova S. N. Pedagogical communication as a dialogue in culture 2002, №. 4.

[2] Vasilika M. Fundamentals of the theory of communication textbook for universities / M.: Gardariki, 2003.

[3] Voronina M.P. Dialog in a lesson in elementary school. - M., 2004, № 6

[4] Kokhanov E. Communication as the interaction of social actors (to the basics of social psychology "public relations"). Management, 2001, № 5.
[5] Lvov M.R. Rhetoric. A culture of speech. Textbook for high schools / - M.: ACADEMIA, 2003.

[6] Maksimova V.I. Russian language and culture of speech: Textbook. / Ed. prof. M.: Gardariki, 2000.

[7] Pavlova L.G. Debate, discussion, controversy. A book for high school students. - M.: Education, 1991.

[8] Passov E.I. Dialogue and communication philosophical problems: Materials of the round table / Questions of Philosophy, 1989, № 7.

[9] Passov E.I. Foreign language lesson in high school. - M.: Education. - 1988.

[10] Solovova, E.N. Methods of teaching foreign languages. Basic course of lectures. - M.: Education. - 2002.

[11] Sulima I. The dialogue of times and cultures. - Public education. 1998. №9 